\title{
Answer and discussion: Abdominal and neuroimaging quiz case
}

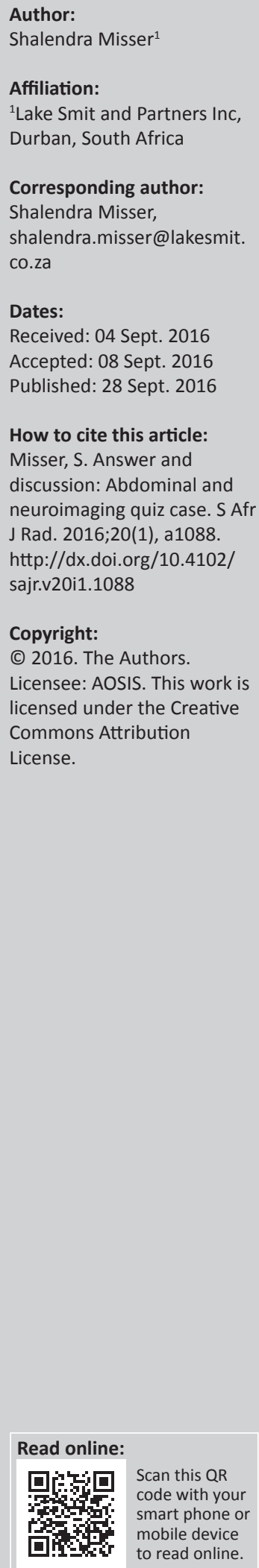

A 40 year old lady had a CT and an MRI scan of her brain for investigation of severe headache following recent recurrent bowel surgery. The post-operative course was complicated by abdominal wall haematoma and she required multiple blood transfusions. Background history of multiple previous bowel resections and chronic anti-inflammatory therapy for inflammatory bowel disease was noted.

It is heartening to note that several good submissions were received for the abdominal and neuroimaging quiz case. Noteworthy responses were received from Drs Melanie Strachan, Francois Roux, and Mohammed Azfar Siddiqui, however no completely correct diagnosis was received.

\section{Answer}

Five years prior to the current presentation, this 40 year old lady was diagnosed with Crohn's disease. She underwent multiple laporotomies for resection of strictured segments of small bowel and was placed on intensive disease modifying therapy including corticosteroids and immunosuppressive agents. Computerised tomography image in Figure 1 demonstrates inflammatory change of the ascending and descending colon with associated 'comb sign' of the respective right and left colic branches. Segmental small bowel and transverse colon wall thickening is noted. In Figure 2 there is marked mural thickening in the descending colon with a long segment stricture, 'comb sign' with hypertrophy of the paracolic vessels and associated fat stranding. Similar inflammatory changes are seen involving a distal small bowel loop in Figure 3. The computerised tomography study therefore demonstrated acute exacerbation with flare up of the bowel-related inflammation due to acute on chronic Crohn's enterocolitis.

The patient was subsequently taken to theatre for laporotomy. The surgery was difficult due to extensive adhesions. Post-operative complication of abdominal wall haematoma and falling haemoglobin level was noted, for which multiple blood transfusions were administered. A week after surgery, the patient developed severe thunderclap type headaches associated with blurring of vision and variable right lower limb paresis. Figure 4, axial noncontrasted CT scan of the brain revealed subtle effacement of the sulcal spaces over the right cerebral hemisphere especially at the frontal and perisylvian region. Note was also made of isodensity over the right frontal surface convexity. This however did not explain the ipsilateral right monoparesis.

MRI study of the brain was arranged to further elucidate the cause of this unusual presentation. T2-weighted (Figure 5) and T1-weighted (Figure 6) MRI sequences confirmed the right frontal gyral swelling with effaced right middle and superior frontal sulci. Subtle gyral swelling was also observed in the parasagittal left frontal precentral region. Figure 7, a coronal FLAIR image showed, in addition to the frontal gyral swelling, an extra-axial fluid collection over the right frontal lobe convexity and in the sulci due to a sliver of subdural and subarachnoid blood respectively. A right sublenticular cyst was also incidentally noted.

Restricted diffusion signal was demonstrated on the b1000 diffusion imaging sequence (Figure 8) as well as corresponding adc shortening (Figure 9) in the right frontal surface collection, in the left paramedian pre-rolandic frontal lobe and a small focus at the right peritrigonal region. The former represented the reduced diffusivity within the extra-axial blood in the right frontal haemorrhage while the latter two areas of restricted diffusion correspond to acute ischaemic change.

The susceptibility weighted imaging (SWI) minimum intensity projection (MIP) sequence images in Figure 10 clearly delineate the presence of subarachnoid blood located within the right superior frontal sulci, right perisylvian sulci, left central sulcus and bilateral parieto-occipital areas. The SWI phase 


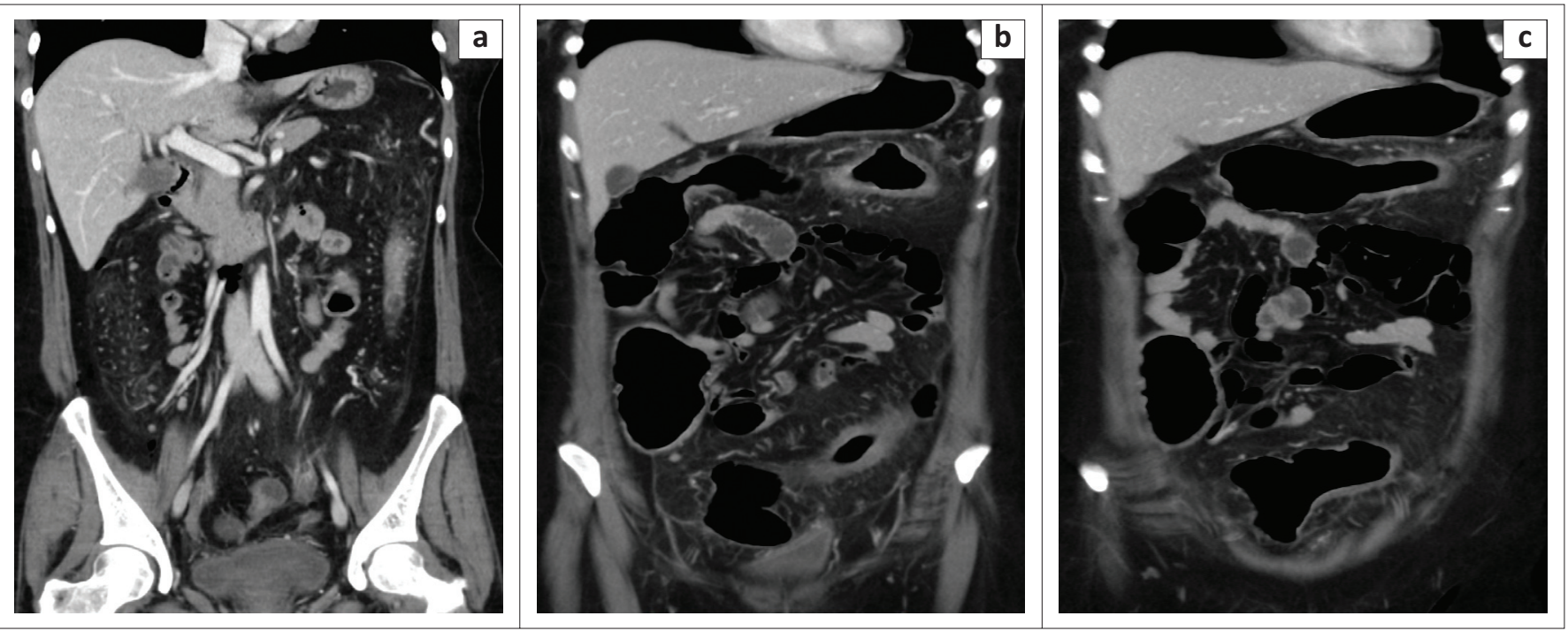

FIGURE 1: Coronal reformat images ( $\mathrm{a}, \mathrm{b}$ and $\mathrm{c}$ ) of the abdomen in venous phase after intravenous (IV) contrast administration.

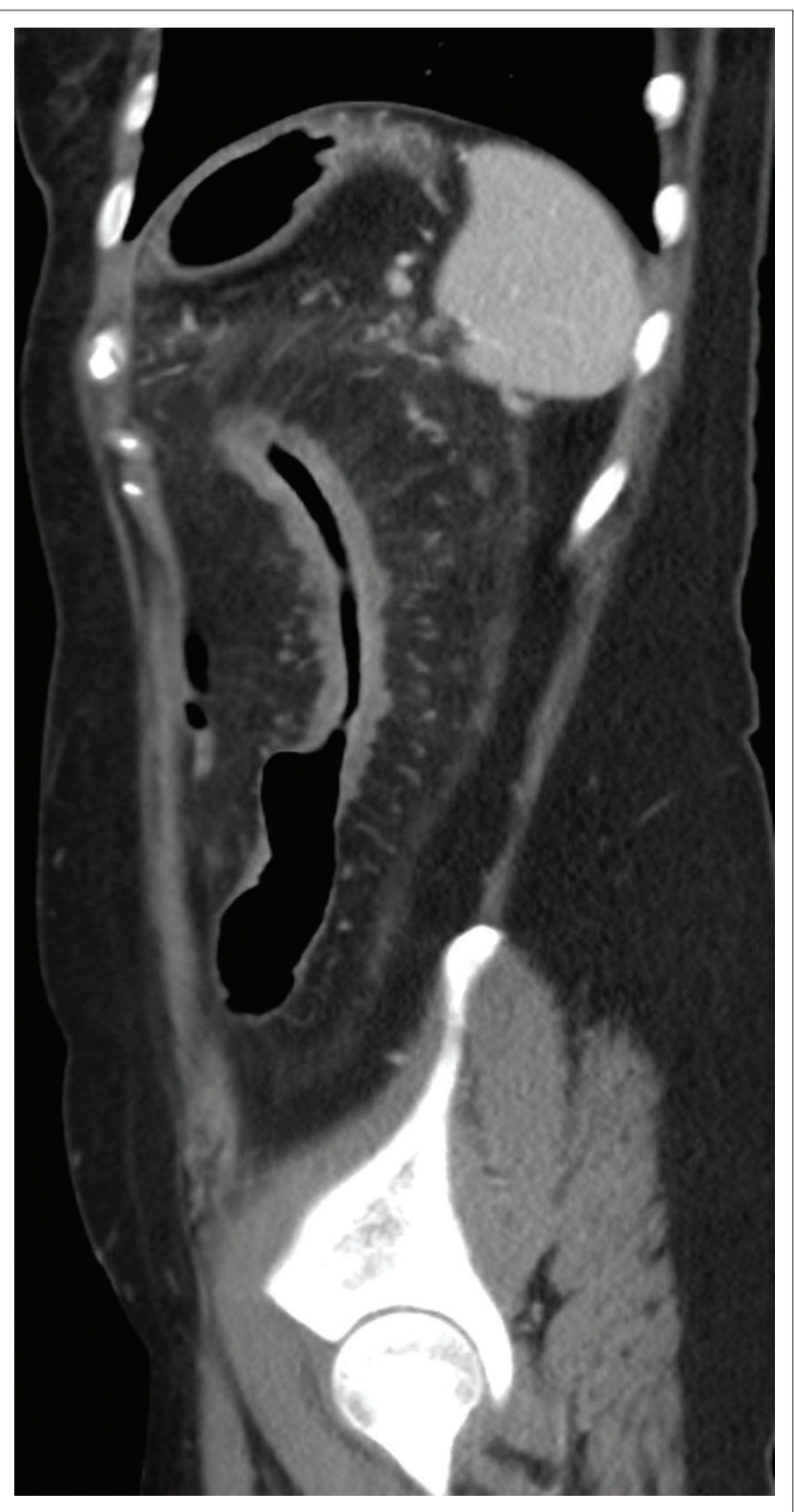

FIGURE 2: Sagittal.

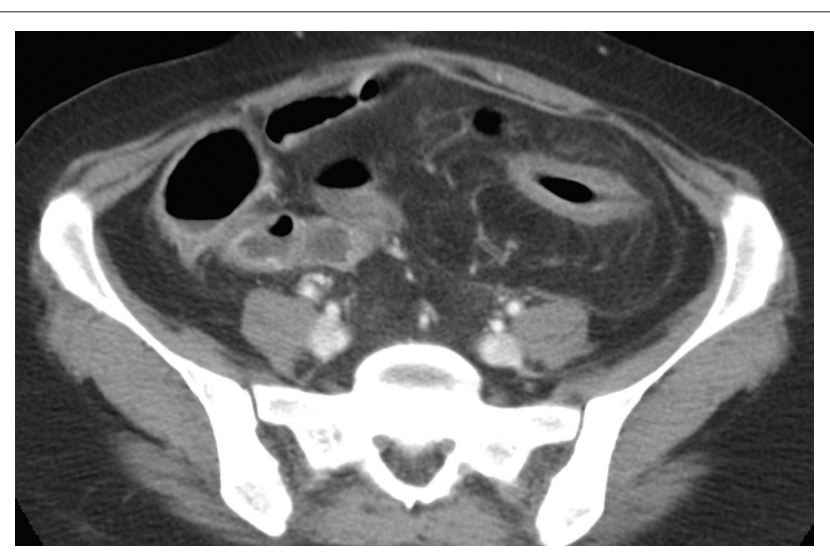

FIGURE 3: Axial images of the abdomen in venous phase after IV contrast administration.

images (Figure 11) confirm that the SWI signal abnormalities are due to blood products with corresponding hypointensity.

A final diagnosis was made of reversible cerebral vasoconstriction syndrome associated with vasospastic ischaemic change in both hemispheres (especially left frontal lobe) secondary to post-operative state, severe blood loss and haemotransfusion. Sadly, the patient succumbed to multiorgan failure and demised before follow-up imaging was possible.

\section{Discussion}

Reversible cerebral vasoconstriction syndrome (RCVS) has recently gained much recognition particularly in the neuroradiological literature. Call-Fleming syndrome is one of the names attached to this syndrome after description by these authors in 1988 of an entity called reversible cerebral segmental vasoconstriction. ${ }^{1}$ Calabrese et al. coined the name of RCVS in $2007 .^{2}$ It is characterised by sudden onset of severe, unremitting headaches (classically described as thunderclap) associated with nausea, vomiting and seizures. In some cases long tract signs attributable to ischaemic injury, may be detected clinically. 


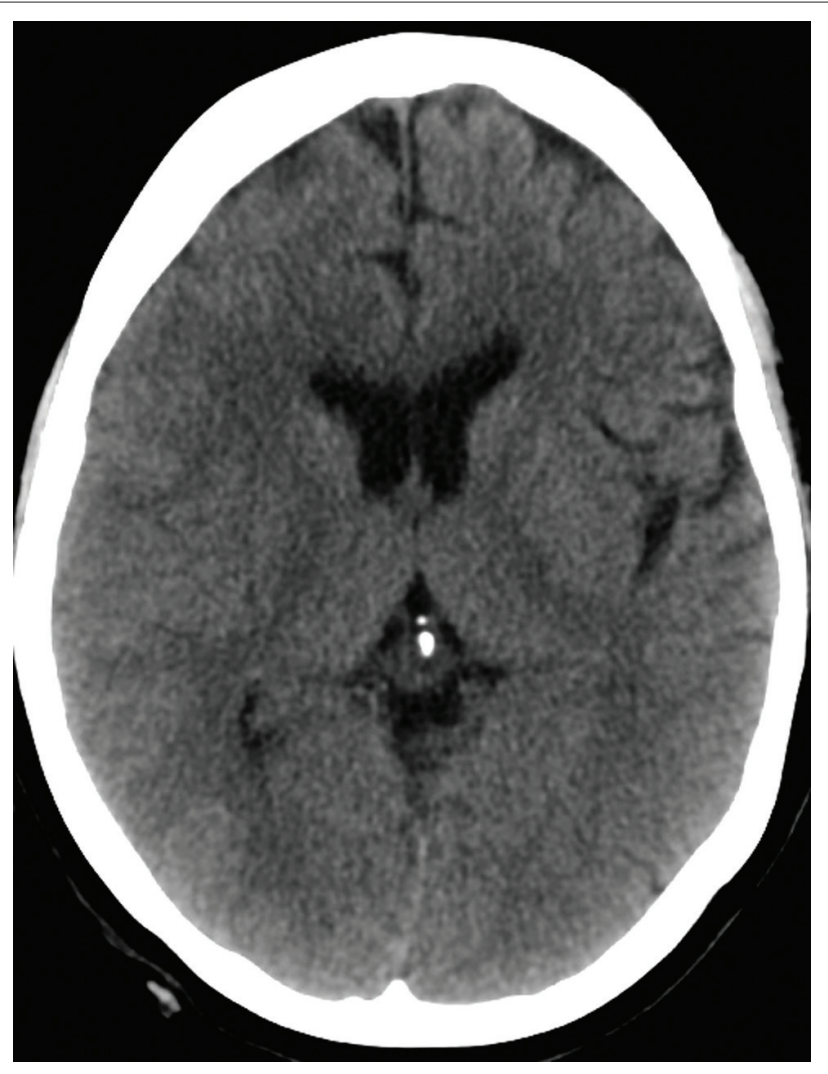

FIGURE 4: Axial noncontrasted CT image.

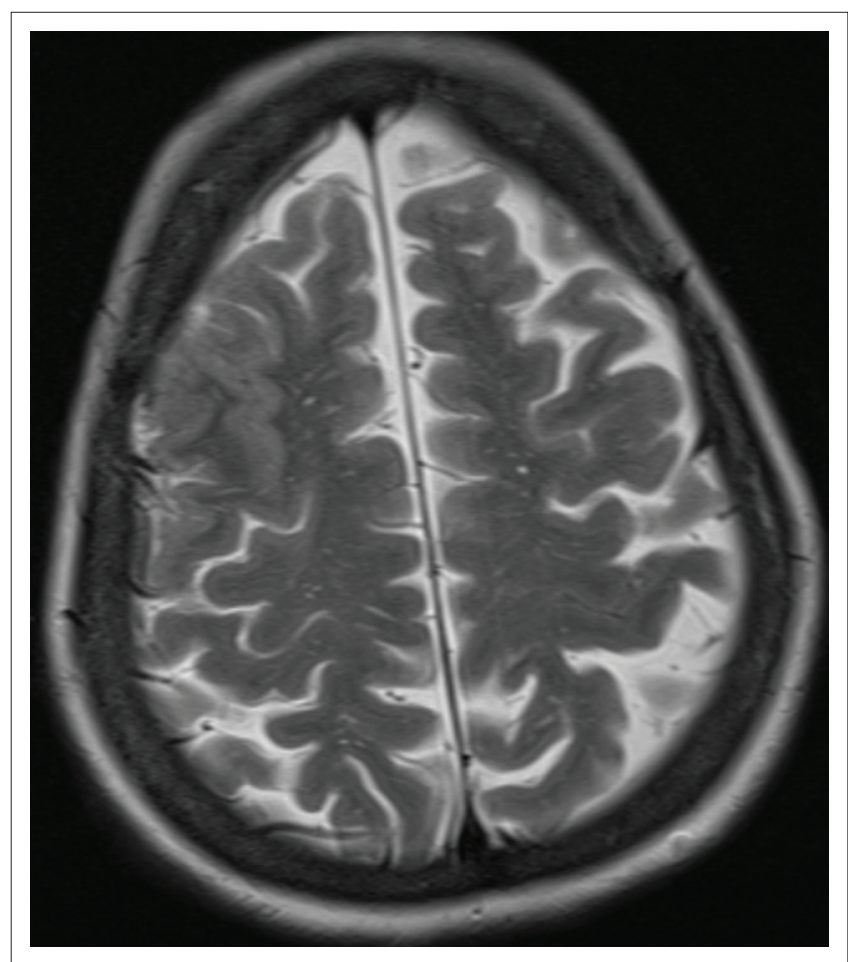

FIGURE 5: Axial T2 image.

Most reports ${ }^{3,4}$ describe a higher preponderance in female patients, particularly in the fourth and fifth decades as well as in the post-partum period. The pathophysiology includes a transient dysregulation in cerebrovascular tone with segmental or focal arterial branch stenoses and areas of post-

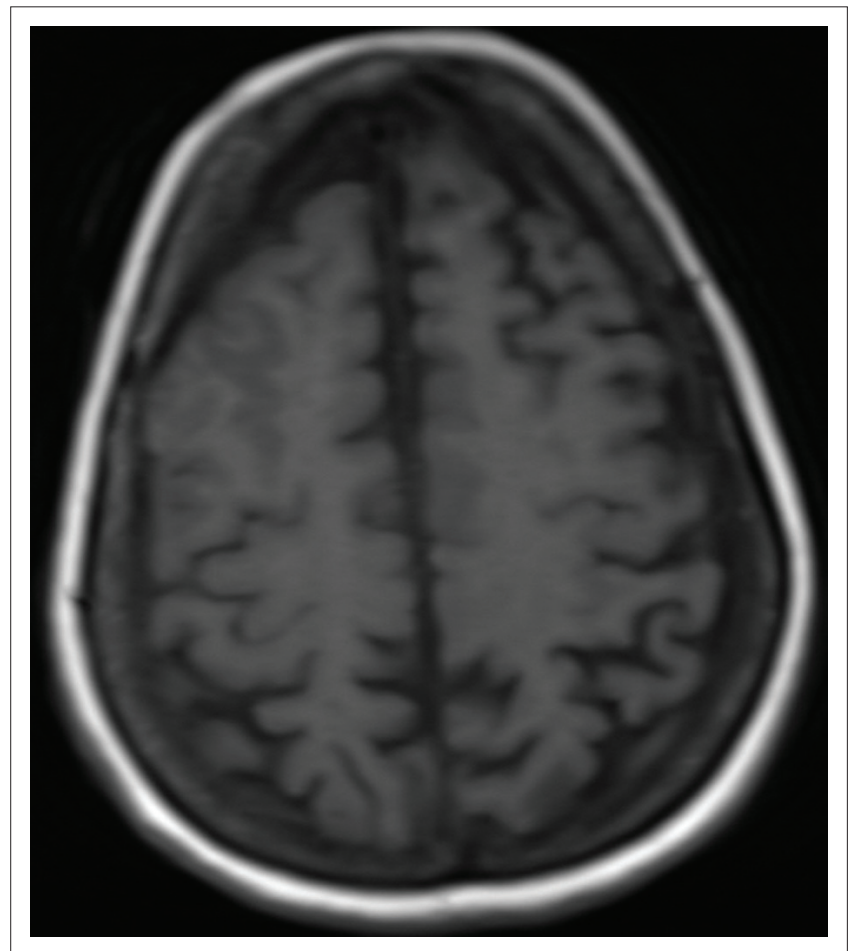

FIGURE 6: Axial T1-weighted MRI image.

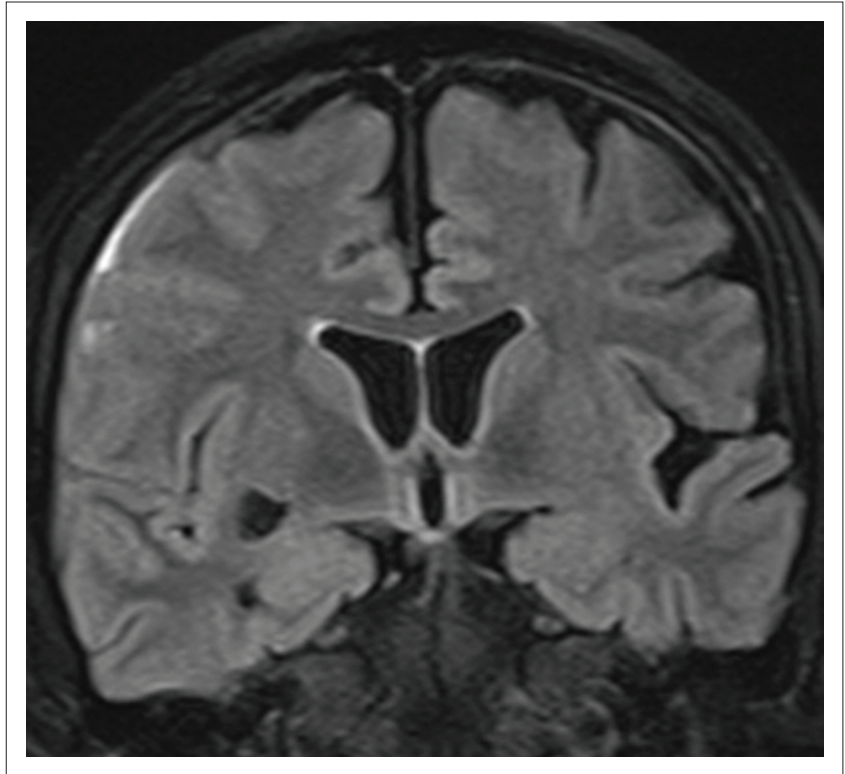

FIGURE 7: Coronal FLAIR MRI image.

stenotic ectasia. ${ }^{4}$ Several precipitating causes and triggers have been identified (Table 1)

Neuroimaging features range from a normal MRI study to convexal subarachnoid haemorrhage, cerebral ischaemic changes, intracerebral haemorrhage to PRES-like lesions. Singhal et al. ${ }^{5}$ showed a normal initial CT or MRI study in $55 \%$ of patients with RCVS and $81 \%$ with positive neuroimaging finding on subsequent studies. Most authors concur that a high index of clinical suspicion is warranted and treatment should be instituted earlier. Some have documented starting treatment despite the absence of any 


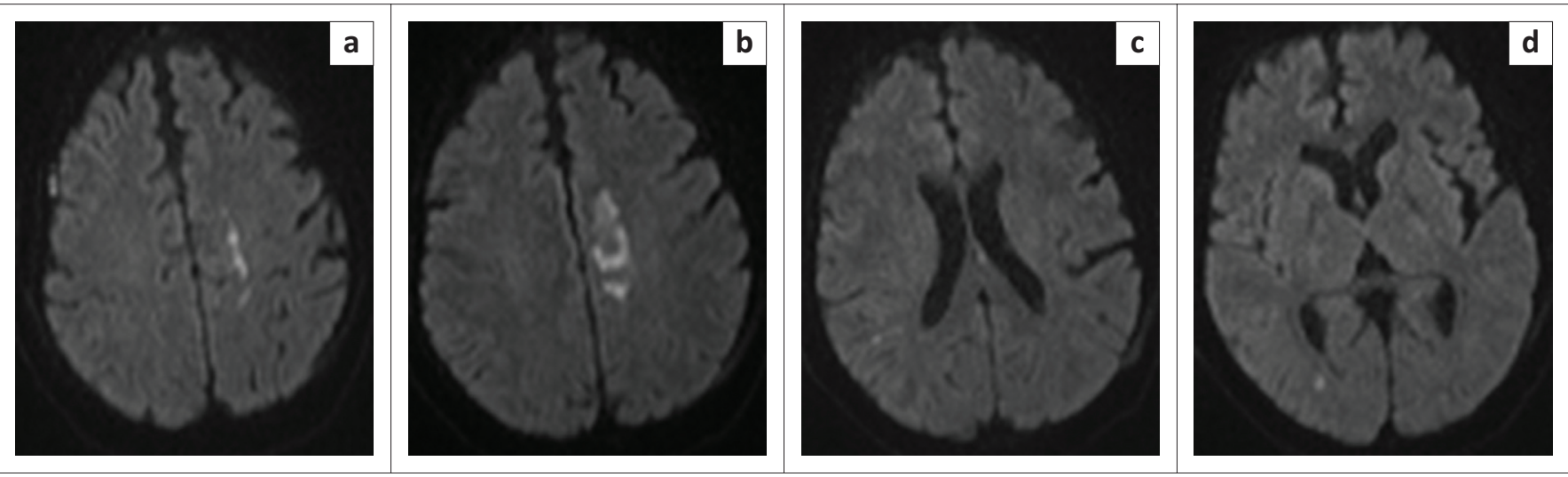

FIGURE 8: Axial DWI b1000 MR images (a-d).
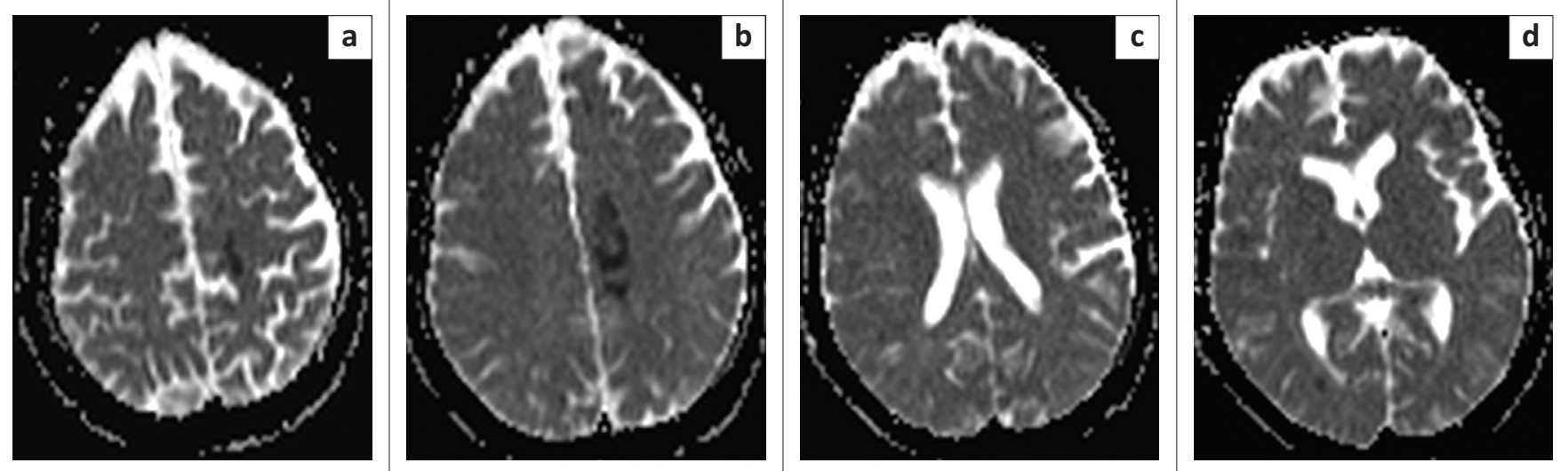

FIGURE 9: Corresponding axial ADC map MR images (a-d).
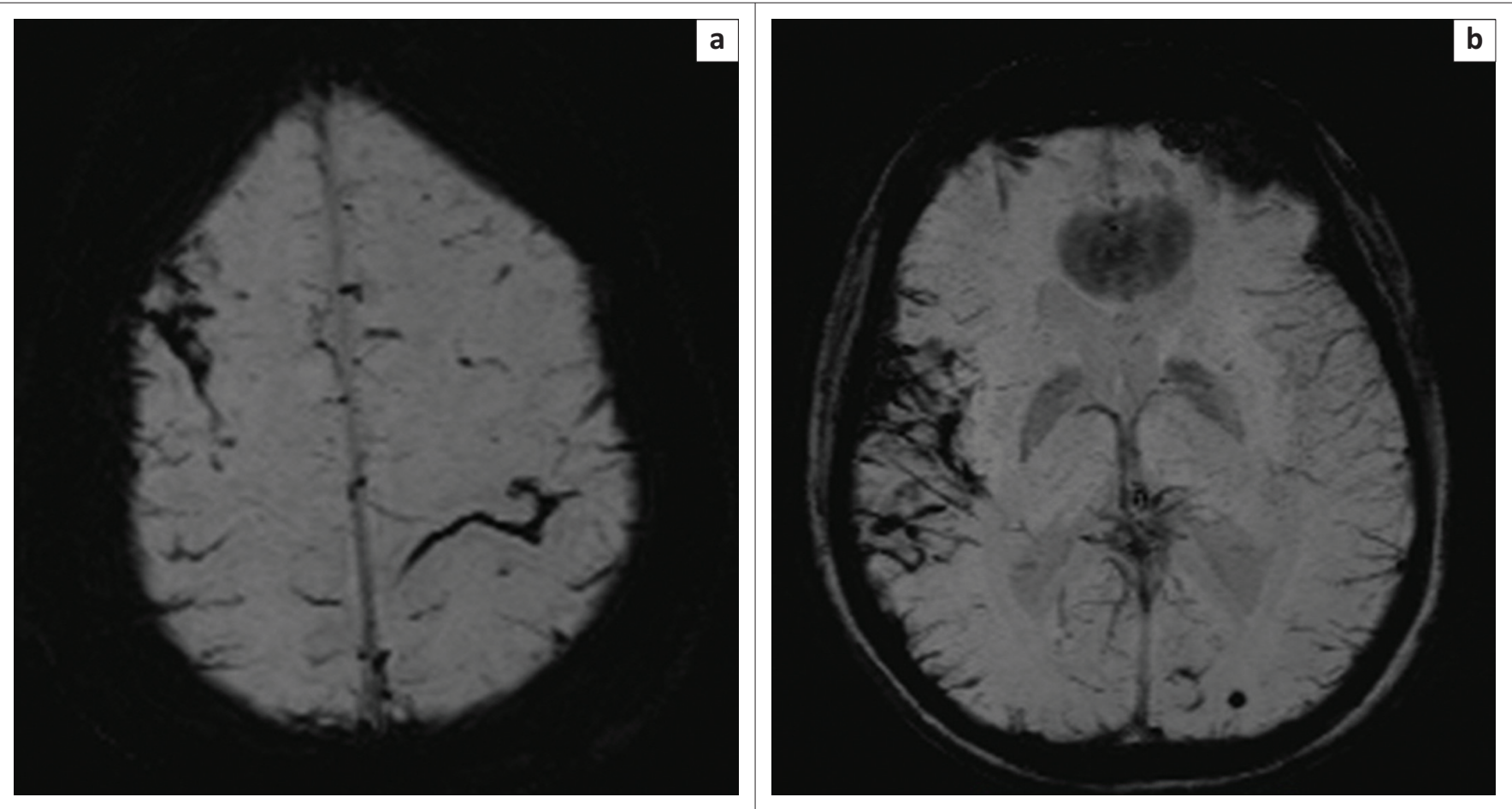

FIGURE 10: Axial SWI MR images ( $a$ and $b$ ) 

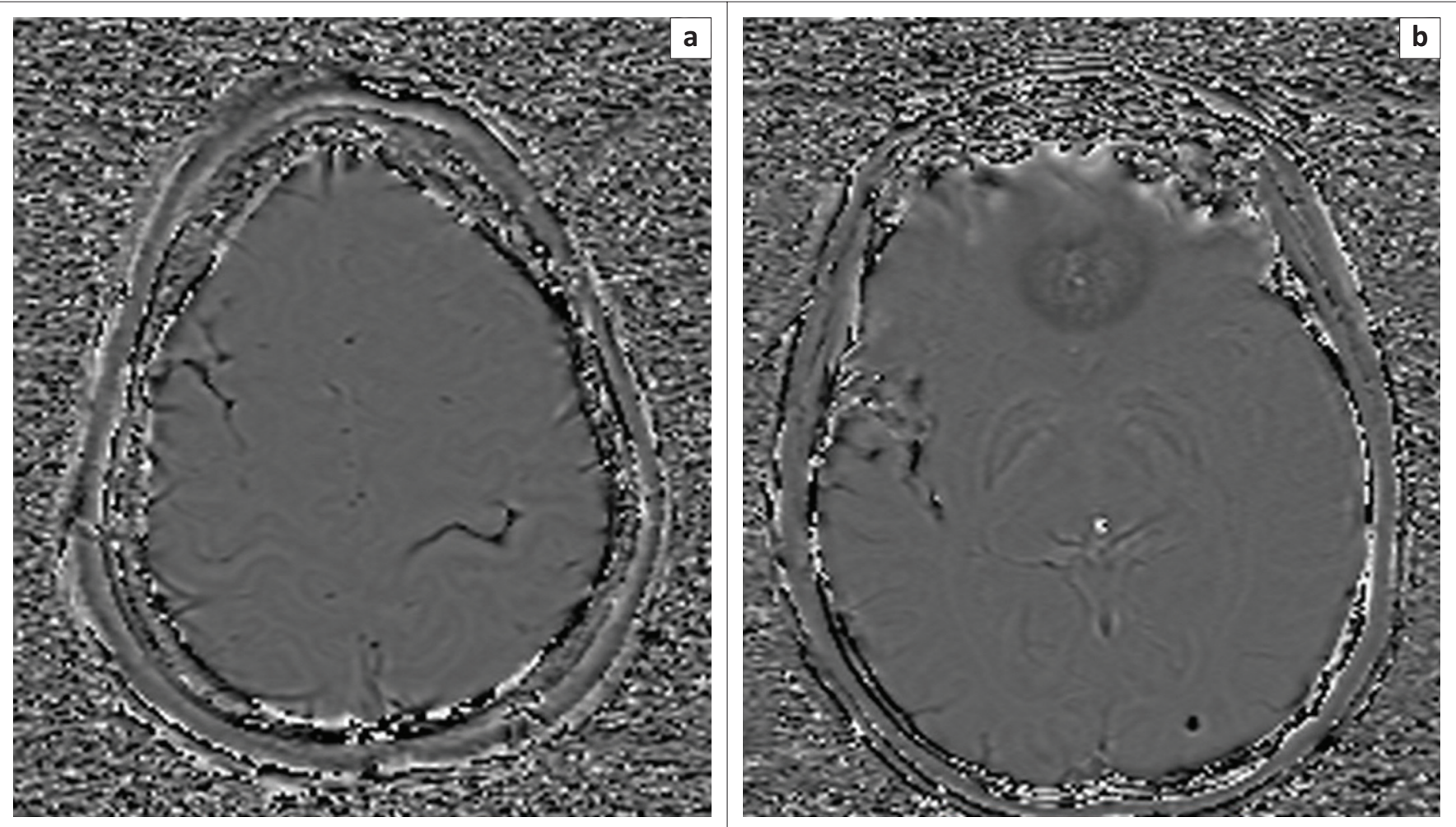

FIGURE 11: Corresponding axial PHASE MR images ( $a$ and $b$ ).

TABLE 1: Precipitating factors and conditions associated with RCVS

\begin{tabular}{ll}
\hline Factor & Condition \\
\hline Post-partum & Post-partum state \\
& Eclampsia or pre-eclampsia \\
& Drug exposure in puerperium \\
Exposure to therapeutic or & Serotonergic drugs e.g. Ssri's \\
recreational drugs & Cocaine, ecstacy, amphetamines, cannabis \\
& Nasal decongestants, pseudoephedrine \\
& Chemotherapy e.g. Tacrolimus, cyclophosphamide \\
& Nicotine patches \\
& Binge alcohol intake \\
& Herbal medication e.g. Ginseng \\
& Catecholamine secreting tumours \\
Phaeochromocytoma & Carcinoid tumours \\
Tumours & Red blood cell transfusion \\
Interferon alpha \\
Erythropoietin \\
Immunoglobulin therapy \\
Porphyria \\
Hypercalcaemia \\
Head trauma \\
Post-surgical state \\
Bath related \\
Weight-loss treatment \\
Airplane descent \\
Sexual intercourse \\
Miscellaneous
\end{tabular}

Source: Ducros A. Reversible cerebral vasoconstriction syndrome. The Lancet Neurology. 2012;11(10):906-917; Ducros A, Boukobza M, Porcher R, Sarov M, Valade D, Bousser MG. The clinical and radiological spectrum of reversible cerebral vasoconstriction syndrome: $A$ prospective series of 67 patients. Brain. 2007;130:3091-3101

significant neuroimaging abnormality on initial studies. For those patients demonstrating convexity subarachnoid haemorrhage (SAH) in the presence of thunderclap headache, RCVS has been shown to be the lead cause of this combination
TABLE 2: Causes of nonaneurysmal convexal SAH..$^{3,4,5}$

\begin{tabular}{|c|c|}
\hline Junger patients $<60$ years old & Older patients $>60$ years old \\
\hline RCVS & Cerebral amyloid angiopathy \\
\hline $\begin{array}{l}\text { Posterior Reversible Encephalopathy } \\
\text { Syndrome }\end{array}$ & Primary angiitis of the CNS \\
\hline Post-partum angiopathy & Cortical vein thrombosis \\
\hline Hypertensive microangiopathy & Cavernoma with recurrent bleeding \\
\hline Thrombocytopaenia & Other cerebral vasculitis \\
\hline Dural venous sinus thrombosis & Anticoagulation related \\
\hline \multicolumn{2}{|c|}{$\begin{array}{l}\text { Source: Ducros A. Reversible cerebral vasoconstriction syndrome. The Lancet Neurology. } \\
2012 ; \text {; 11(10):906-917. http://dx.doi.org/10.1016/S1474-4422(12)70135-7; Ducros A, } \\
\text { Boukobza M, Porcher R, Sarov M, Valade D, Bousser MG. The clinical and radiological } \\
\text { spectrum of reversible cerebral vasoconstriction syndrome: A prospective series of } 67 \\
\text { patients. Brain. 2007; 130:3091-3101. http://dx.doi.org/10.1093/brain/awm256; Singhal } \\
\text { AB. Diagnostic challenges in RCVS, PACNS, and other cerebral arteriopathies. Cephalalgia. } \\
\text { 2011; 31(10):1067-1070. http://dx.doi.org/10.1177/0333102411410084 }\end{array}$} \\
\hline
\end{tabular}

BOX 1: Summary of the critical elements for diagnosis of RCVS.

1. No evidence of aneurysmal SAH
2. Angiography(CTA, MRA or DSA) demonstrating segmental cerebral artery
vasoconstriction
3. Normal or near-normal CSF analysis (protein $<80 \mathrm{mg} \%$, leukocytes $<10 / \mathrm{mm}^{3}$,
normal glucose)
4. Severe, acute headaches, with or without other neurological signs and symptoms
5. Reversibility of angiographic abnormalities within 12 weeks after onset or
autopsy proven. Source: Ducros A. Reversible cerebral vasoconstriction syndrome. The Lancet Neurology. 2012;11(10):906-917

in the last 10 years. ${ }^{6}$ Other causes of non-aneurysmal convexal SAH are listed in Table 2. Convexal SAH may be quite subtle on baseline CT scan and is best assessed on SWI MIP sequences that demonstrate blood in the sulci over the cerebral surface convexities. SWI phase images are useful in confirming that the paramagnetic SWI sulcal abnormality is due to haemorrhage, rather than calcification or gyral surface metal deposition. 
TABLE 3: Useful list of features distinguishing RCVS from PANCS.

\begin{tabular}{|c|c|c|}
\hline Feature & PANCS & RCVS \\
\hline Demographics & $\begin{array}{l}\text { More frequent in middle-aged } \\
\text { males }\end{array}$ & Primarily women aged 20-40 \\
\hline Clinical precipitant & Absent & Frequently identifiable \\
\hline Clinical headache & Insidious onset & Thunderclap or acute severe \\
\hline $\begin{array}{l}\text { Clinical cognitive } \\
\text { impairment }\end{array}$ & Frequent & Unusual \\
\hline CSF & $\begin{array}{l}\text { Abnormal (increased protein, } \\
\text { pleocytosis) }\end{array}$ & $\begin{array}{l}\text { Normal or minimal protein } \\
\text { increase }\end{array}$ \\
\hline \multirow[t]{2}{*}{ MRI } & \multirow{2}{*}{$\begin{array}{l}\text { Abnormal in most patients. } \\
\text { Small infarcts. Diffuse white } \\
\text { matter lesions. Mass lesions }\end{array}$} & $\begin{array}{l}\text { Normal initially in some } \\
\text { patients }\end{array}$ \\
\hline & & Can have infarcts, PRES, SAH \\
\hline \multirow[t]{3}{*}{ Angiography } & \multirow{3}{*}{$\begin{array}{l}\text { Can be normal. Single or } \\
\text { multiple abnormalities } \\
\text { (stenoses, mural irregularities, } \\
\text { avascular mass lesions) }\end{array}$} & Abnormal \\
\hline & & $\begin{array}{l}\text { Multiple areas of stenoses and } \\
\text { dilatations }\end{array}$ \\
\hline & & Reversible in 6-12 weeks \\
\hline Biopsy & Vasculitis & Normal \\
\hline
\end{tabular}

Source: Singhal AB. Diagnostic challenges in RCVS, PACNS, and other cerebral arteriopathies. Cephalalgia. 2011;31(10):1067-1070; Ducros A, Wolff V. The typical thunderclap headache of reversible cerebral vasoconstriction syndrome and its various triggers. Headache. 2016; 56:657-673

The diagnostic criteria for RCVS are shown in Box 1. A principal feature is the absence of any aneurysm of the intracranial vessels to account for the SAH. Digital subtraction angiography (DSA) is the gold standard of intracranial cerebral arteriography with the best spatial and temporal resolution for the demonstration of peripheral smaller calibre vessels. Disadvantages of DSA include the invasiveness, potential for vascular injury, use of radiation and intravenous contrast. Currently, non-invasive indirect methods of angiography are primarily used to assess the intracranial vessels in the setting of SAH.

Computerised tomography angiography (CTA) has several advantages including excellent spatial resolution, reproducibility for follow-up imaging, short imaging time as well as possibility to be performed at the time of the initial CT scan. Branch vessel depiction on volume rendered reformat CTA images shows the smaller calibre vessels well up to the third order divisions. A 'string of beads' sign may be seen with sequential areas of vascular narrowing in RCVS (Figure 12). Multidetector CT scanners of today have significantly improved resolution, comparable to DSA. Disadvantages of CTA include lack of scope for intervention, use of radiation and intravenous contrast.

Magnetic resonance angiography (MRA) can be performed immediately at the time of MRI and if available is a useful tool for assessment of the intracranial vasculature. The relatively poorer spatial resolution makes assessment of the peripheral or smaller calibre branches difficult on MRA when compared to DSA or CTA. The non-invasive nature, absence of ionising radiation and time of flight acquisition which can be performed without gadolinium are attractive advantages of MRA. Lack of availability in the acute setting, long sequence acquisition time and sedation or anaesthesia requirement are some disadvantages of MRA.

Cerebrospinal fluid (CSF) analysis for protein, glucose and cell content is an important diagnostic criterion for RCVS. In
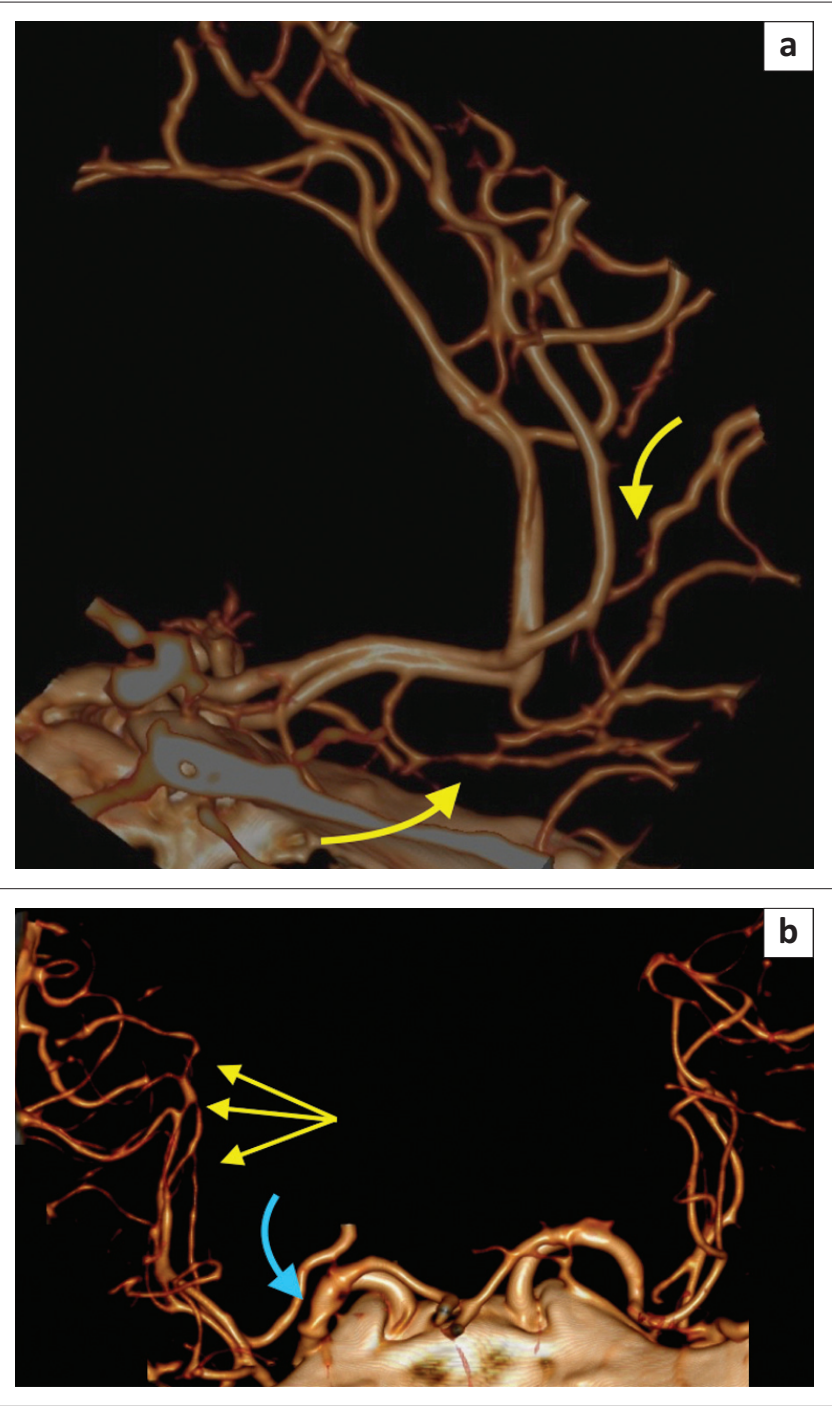

FIGURE 12: (a) Curved yellow arrows showing segmental areas of subtle vascular narrowing at the $\mathrm{A} 3$ branches of the anterior cerebral arteries; (b) Curved blue arrow demonstrating focal reduction in calibre of the right middle cerebral artery M1 segment. Straight yellow arrows showing sequential stenoses in the right middle cerebral arterial branches due to severe vasoconstriction.

the principal differential diagnosis of primary angiitis of the central nervous system, the CSF may show mild pleocytosis and elevated protein level. These are not features of RCVS. Dependant on the amount of $\mathrm{SAH}$, the value of CSF assessment may be variable as the parameters are influenced by the presence of blood.

Reversibility of angiographic abnormalities within twelve weeks of the initial presentation requires demonstration of partial or usually complete resolution of the vasospasm shown on initial vascular imaging. In cases of death occurring before repeat imaging could be performed, postmortem confirmation of absence of vasculitis, intracranial atherosclerosis and aneurysm would be contributory to the diagnosis of RCVS.

The primary diagnostic dilemma is differentiating RCVS from primary angiitis of the central nervous system (PANCS). RCVS is commonly seen in women between 20 and 40 years of age whereas PACNS is more often encountered in middle-aged 
men. A precipitating factor is frequently identifiable in RCVS but not so in PACNS where the headache is of insidious onset. Generally, in most patients with RCVS, the angiographic changes resolve completely or substantially within 12 weeks. It is crucial to confirm absence of an intracranial aneurysm, as aneurysmal SAH is also an important differential diagnosis. Further differential considerations are venous sinus thrombosis and arterial dissection of the carotid and/or vertebral arteries which may also present with acute thunderclap headaches. These conditions may not be diagnosable on plain CT scans or by CSF analysis. MRI to assess the parenchyma as well as complete arterial and venous phase angiography of the intracranial and extracranial vessels is therefore indicated to exclude these differential diagnoses.

Treatment is empirical and includes calcium-channel blockers and high dose corticosteroids. ${ }^{6}$ Removal or reduction of an offending precipitant is vital. The prognosis is uncertain and influenced by several factors, but most patients recover completely. In cases with established infarction demonstrated on diffusion weighted MRI, the prognosis tends to be worse and death may unfortunately ensue as in the patient presented.

\section{Acknowledgements Competing interests}

The authors declare that they have no financial or personal relationships which may have inappropriately influenced them in writing this article.

\section{References}

1. Call GK, Fleming MC, Sealfon S, Levine H, Kistler JP, Fisher CM. Reversible cerebral segmental vasoconstriction. Stroke. 1988;19:1159-1170. http://dx.doi.org/10. 1161/01.STR.19.9.1159

2. Calabrese LH, Dodick DW, Schwedt TJ, Singhal AB. Narrative review: Reversible cerebral vasoconstriction syndromes. Annals of Internal Medicine. 2007; 146(1):34-44. http://dx.doi.org/10.7326/0003-4819-146-1-200701020-00007

3. Ducros A. Reversible cerebral vasoconstriction syndrome. The Lancet Neurology. 2012;11(10):906-917. http://dx.doi.org/10.1016/S1474-4422(12)70135-7

4. Ducros A, Boukobza M, Porcher R, Sarov M, Valade D, Bousser MG. The clinical and radiological spectrum of reversible cerebral vasoconstriction syndrome: $A$ prospective series of 67 patients. Brain. 2007;130:3091-3101. http://dx.doi. org/10.1093/brain/awm256

5. Singhal $A B$. Diagnostic challenges in RCVS, PACNS, and other cerebra arteriopathies. Cephalalgia. 2011;31(10):1067-1070. http://dx.doi.org/10.1177/ 0333102411410084

6. Ducros $A$, Wolff $V$. The typical thunderclap headache of reversible cerebral vasoconstriction syndrome and its various triggers. Headache. 2016;56:657-673. http://dx.doi.org/10.1111/head.12797 